\title{
The impact of virtual reality technology on digital media teaching
}

\section{LuoChanggen, YuanXuemei}

\author{
Jiangxi Environmental Engineering Vocational College,Ganzhou 341000,China
}

\begin{abstract}
Key word: Virtual Reality Technology, Digital media teaching, Interactive environment, Curriculum construction
\end{abstract}

\begin{abstract}
With the implementation of the new educational reform and the advent of the digital era, the traditional classroom teaching model has been unable to meet the current needs of teaching, therefore, this research will combine virtual reality Technology with digital media teaching course, and provide a new solution for improving the existing classroom teaching mode. Taking the architectural art class as an example, the teacher uses virtual reality technology to display three-dimensional buildings and students wear helmets, so that they can feel the art of architecture in person. This paper expounds the effect of multimedia digital teaching based on VR technology, and expounds the influence of VR technology on digital multimedia teaching based on this. Finally, through classroom experiment demonstration of digital multimedia teaching based on VR technology, and some suggestions of discipline construction based on VR technology has been put forward, which provides a new reference for the improvement of modern teaching methods.
\end{abstract}

\section{Introduction}

The birth and development of digital media technology is based on the development and popularization of computer, it is a new comprehensive and practical information technology at the end of twentieth Century, its purpose is to "establish a more harmonious artificial environment". It is the fusion of digital image processing, computer graphics, multimedia technology, sensor and measurement technology, virtual and artificial intelligence and other disciplines in one, establishes a realistic virtual interactive three-dimensional space environment for people, and respond the real-time activities or operations for people, which makes people feel like being in the real world. It will have a great impact on traditional multimedia teaching that taking the virtual reality technology into the teaching process, multimedia teaching from 2D to 3D interaction, and construct a virtual, high simulation teaching environment.

\section{VR technology and modern digital teaching scene simulation}

The use of VR technology in the modern digital teaching can be integrated multimedia, computer graphics and artificial intelligence technology, can realize the creation of the real situation, can express the teaching content of three-dimensional space, environment and other distinctive interpersonal exchange. In the digital multimedia teaching process, the use of VR technology can make students more intuitive and natural to participate in the virtual environment, participate in the teaching content in a variety of forms, realize the interaction between students of information, make the abstract teaching content becomes more specific and vivid, improve the efficiency of the creation of teaching situations and teaching quality. 

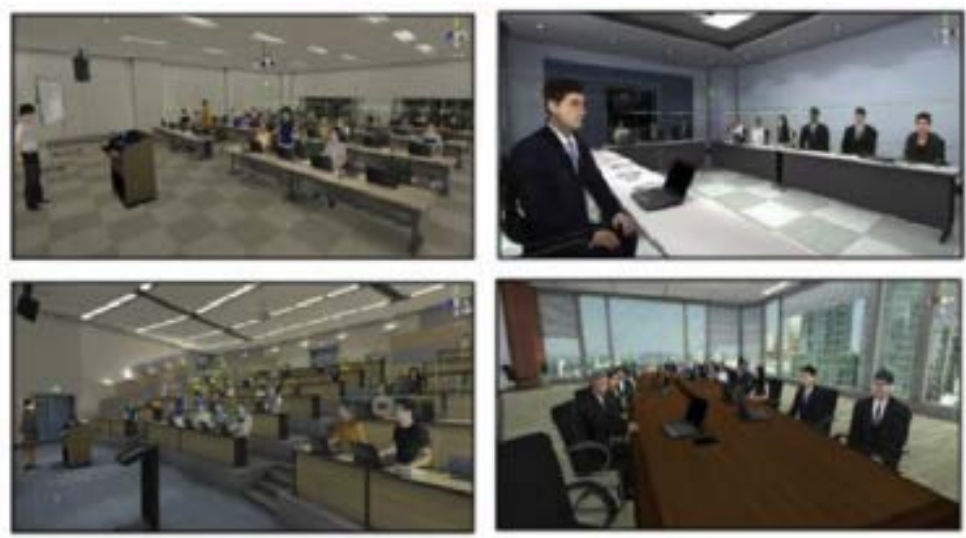

Figure 1 Simulation of teaching activities based on VR Technology

Figure 1 is the simulation of digital multimedia teaching based on VR technology, the real classroom and the interaction between the students can be simulated by use of VR technology, then the activity of the classroom atmosphere and the vividness of the course content are improved. For example, in the architectural art class, the teacher can reproduce the real architecture using VR technology, and through the operation of the building size and height, to enable students to understand the specific construction, but also can allow students to wear a helmet, their own experience and interaction, and can also modify the architecture model, to enable students to feel the architectural art.

\section{The influence of VR technology on digital multimedia teaching}

VR digital media technology provides a realistic environment for teaching. Since the introduction of digital media technology into the teaching course based on VR, college education is no longer just relying solely on books and teachers for curriculum teaching, but also combining virtual animation and scene creation to make abstract theory become concrete, For example, VR technology can be used to display historical events vividly in class, in order to simulate the evolution of social history, the atomic structure and mechanical movement can be three-dimensional presentation, which makes the learning process more vivid. Compared with the traditional teaching methods, the vivid and specific teaching process has more appeal to the students. It can arouse the enthusiasm of the students and improve the efficiency of the students' learning.

Arouse students' multi senses into study. The multimedia technology based on VR can make the boring teaching content vivid, vivid and visual, and make the students receive the knowledge with great interest, and improve the students' imagination and exploration ability. The virtual reality teaching environment and realistic environment more realistic, which is more easy to arouse students' eyes, mouth, heart, hands and other organs. In the three-dimensional, full range of teaching environment, students have more profound perception of knowledge, and put more senses into learning, which improves the comprehensive ability of learning.

The space and scale of teaching have been expanded. With the development of cloud technology, multimedia technology based on VR expands the teaching space and scale, and through the Flash animation resources and 3D Web visualization technology, we can easily help students to supplement the knowledge outside the classroom, and by means of distance learning, learning becomes easier and smoother.

\section{Teaching effect and course construction of digital media art based on VR Technology}

Teaching effect discussion. In order to study the effect of VR technology on digital multimedia 
teaching effect, by using the method of short term teaching experiment, the experimental group were divided into two groups, one group was the experimental group and the other group was the control group, the experimental group using VR technology to create teaching situation, another group according to the traditional class type class, by comparing the teaching effect, we get the data shown in table 1.

Table 1 The verification of VR digital media teaching methods

\begin{tabular}{|c|c|c|}
\hline Experiment item & Experience group & control group \\
\hline $\begin{array}{c}\text { Number of people interested in } \\
\text { classroom content }\end{array}$ & 95 & 78 \\
\hline $\begin{array}{c}\text { Number of people impressed by } \\
\text { the content of the class }\end{array}$ & 32 & 81 \\
\hline Number of Classroom interaction & 88 & 60 \\
\hline $\begin{array}{c}\text { Number of people having positive } \\
\text { response in Classroom }\end{array}$ & 82 & 68 \\
\hline $\begin{array}{c}\text { Number of people having } \\
\text { excellent teaching test results }\end{array}$ & 92 & 22 \\
\hline
\end{tabular}

As shown in Table 1, in the course of the experiment some abstract courses has been selected, through testing classroom interest, understanding of classroom content, classroom atmosphere and students' test results, the effectiveness of VR digital media teaching methods was verified. The experimental results show that the VR digital multimedia teaching method can effectively mobilize the enthusiasm of students, active classroom atmosphere, and the understanding of the teaching content is profound, student performance has been significantly improved, which proves the method to improve the teaching effect.

Curriculum construction. The development of VR digital media teaching course needs not only the innovation of teaching methods, but also the support of modern science and technology, therefore, teachers are required to have some technical bases, such as those from multimedia or computer industry. In the course of construction, the school should strengthen the training of teachers, teachers' use of digital multimedia technology should be improved, teachers should be developed to meet the requirements of VR digital multimedia technology, which can improve the teachers' comprehensive quality and professional skills.

In the course of construction, the structure of courses should be adjusted, students also need to firmly grasp professional basic knowledge, the abstract theory can be used in conjunction with the VR multimedia technology and teaching practice in the course of all-round, so as to enhance students' understanding of the course.

With the continuous development of new teaching reform and implementation of modern VR technology, the school needs to reform the traditional teaching method, VR technology will be introduced into the real curriculum practice, scientific research and teaching can strengthen the docking, the use of VR technology in digital multimedia course, so as to improve the teaching effect.

\section{Conclusion}

In order to study the teaching effect of teaching methods based on VR technology, taking the application of VR technology in architectural art class as an example, the influence of modern teaching based on VR technology on multimedia digital teaching is discussed. Finally, through classroom experiment demonstration of digital multimedia teaching based on VR technology, by comparing the development of the experimental group and the control group, can effectively 
promote the classroom atmosphere by using VR technology, which enables students to understand the teaching contents more deeply, and can effectively improve student achievement. Digital multimedia teaching based on VR technology is still in the initial stage, there is still a long way to go for long-term development. Therefore, we should continue to explore innovative teaching methods, and strive to improve teaching effectiveness, and provide technical support for the improvement of modern teaching level.

\section{Reference}

[1] Feng Wenbo, Luo Weiliang. Research on the technology art training system of digital media art [J]. Modern Decoration (Theory), Vol.33 (06), (2011), p.75-76.

[2] Liu Juemin. Discussion on the training of professionals in Digital Media Arts [J]. Journal of Popular literature and art, Vol.29 (20), (2012), p.265-266.

[3] Jing Yu. Exploring the development of digital media (Art / Technology) major to digital media. [J]. China Law Education Research, Vol.11 (01), (2012), p.150-165

[4] Li Aijuan. The guiding role of constructivist learning theory in courseware development [J]. Journal of Teaching and Management, (11), (2007), p.68-69.

[5] Chen Li. Interactive teaching model and interactive teaching hierarchy for distance learning [J]. China distance education, No.5, (2004), p.24-28

[6] Du Shuying. Media and its significance to aesthetic art [J]. Literary Review, No.04, (2007), p.23-30

[7] Qiu Guopeng, Lin Zibo. New thoughts on art communication in the information age [J]. Art Science and Technology. No.02, (2007), p.50-52

[8] Gong Zhengyuan: On the essence of research study [J]. Modern Primary and Secondary education, No.12, (2001), p.22-23.

[9] Gao Xin. Research in technical aesthetics (Part I) [J]. Modern Communication(Journal of Communication University of China). No.03, (2011), p.69-75

[10] Yao Junxi, Postmodern sublime aesthetics of Lyotarod[J]. Nanjing Journal of Social Sciences. No.08, (2006), p.24-29

[11] Guan Yonggang. Reverse engineering data processing technology based on Geomagic [J]. Science and Technology Innovation Herald. Vol.33, (2011) , p.73

[12] Liu Yan, Hong Zhifeng, Qin Jianbo. Study on 3D modeling technology based on graphics and image [J]. Digital Technology and Application. No.05, (2011) , p.134-135

[13] Gao Lin. Overview of information visualization. [J]. Industrial \& \& Science Tribune. Vol.10 (08), (2011) , p.92-93

[14] Qiao Jie, Guo Junhan, Lan Tianliang. Three-dimensional image based modeling for reconstruction of cultural relics [J]. Sciences of Conservation and Archaeology. Vol.23 (01), (2011) , p.68-71

[15] Zhou Siyue, Gong Zhenbang. Discussion of the definition of virtual reality [J]. Computer Simulation, Vol.23 (9), (2006), p.219-222 